\title{
Las consecuencias de la Guerra Civil española en los niños de la República: de la dispersión al exilio ${ }^{1}$
}

\author{
ALICIA ALTED VIGIL \\ (Universidad Nacional de Educación a Distancia)
}

La guerra civil española de 1936-1939 estalló en medio de una Europa azotada por la crisis económica y la agitación social producto de la radicalización de posturas de clase, en las que un proletariado politizado se enfrentaba a una burguesía que se debatía entre la impotencia y la inacción en el seno de unas democracias parlamentarias debilitadas. Esta situación fue caldo de cultivo para el auge de movimientos nacionalistas y de formaciones frente populistas. Dentro de este marco, las elecciones de febrero de 1936 habían dado en España el triunfo a los grupos políticos que un mes antes firmaron el pacto constitutivo de un Frente Popular integrado por republicanos, socialistas y comunistas y que habia surgido por oposición a un bloque contrarrevolucionario, en el que se agrupaban las distintas fuerzas de la derecha. Pocos meses después, el 17 de julio, se producía una sublevación militar, con el apoyo de los elementos integrantes de ese bloque, que muy pronto derivó en una guerra civil. En ella, los componentes ideológicos y de clase dividieron a la sociedad española en dos bandos antagónicos que pugnaban por imponer su propia concepción de la realidad. De un lado, la revolución popular, el pueblo en armas contra unas clases que habían controlado secularmente el poder. De otro, estas clases que, legitimadas por la jerarquía eclesiástica, respondian con una contrarrevolución de corte nacionalcatólico.

La guerra civil española fue la primera explosión de esa profunda crisis en la que estaba inmersa Europa que conduciria a la segunda guerra mundial. Esto explica, en gran parte, el impacto que produjo en los distintos

\footnotetext{
1 Este texto es una versión revisada y actualizada de la ponencia presentada al Congreso $L a$ guerra dei bambini. Da Sarajevo a Sarajevo (Sesión: "ll bambino vittima, testimone, giudice. L'esperienza della guerra e l' immagine sociale dell'infanzia"), organizado por la Università di Perugia con la colaboración de UNICEF, Perugia, Villa La Colombella, octubre de 1994.
} 
sectores de la opinión pública y entre los intelectuales, así como las posturas tomadas por los gobiernos de otros países que llevaron a una internacionalización temprana del conflicto. Desde el principio, Italia y Alemania apoyaron militarmente a los sublevados. De otro lado, la URSS y en menor medida México se aprestaron a ayudar al gobierno legítimo de la República. Inglaterra, bajo la presión de un gobierno conservador que recelaba de una República inmersa en un proceso revolucionario, propició, con el apoyo de Estados Unidos, una política de no intervención que contribuyó a asegurar la victoria en la guerra a los militares sublevados. En cuanto a Francia, aunque se adhirió formalmente a los acuerdos del comité de no intervención, el gobierno de Frente Popular presidido por León Blum se dividió profundamente entre los comunistas partidarios de la ayuda militar a la República y los radicales temerosos por la reacción de la derecha ante esa ayuda.

La guerra presentó el carácter de guerra total. Afectó a toda la población y constituyó para Alemania un teatro de ensayo de principios y técnicas militares que luego utilizaría en los años de la segunda guerra mundial, en especial los bombardeos a ciudades abiertas. En este marco, los niños fueron los primeros afectados, pues nada más estallar la guerra miles de hogares se deshicieron porque los padres se incorporaron al frente, tuvieron que huir, sufrieron la cárcel o fueron fusilados. El desamparo en el que quedaron ante estas situaciones se acentuó en las zonas cercanas a los frentes, en donde pronto hicieron mella los bombardeos, la escasez de alimentos y las enfermedades derivadas del hacinamiento y las malas condiciones higiénicas. Refugios e interminables colas de personas en espera de víveres se convirtieron en imágenes cotidianas de estos niños de la guerra? ${ }^{2}$.

Dado el carácter ideológico de la guerra civil no puede extrañar que los niños fueran el primer punto de mira de los dirigentes políticos. Para unos y otros ellos eran las futuras generaciones llamadas a consolidar el triunfo de la revolución popular o de la contrarrevolución nacionalcatólica. Por otra parte, las imágenes de niños, mujeres y ancianos indefensos frente a la destrucción y crueldad de la guerra se convirtieron en uno de los mejores intrumentos de una propaganda que perseguía tanto la legitimación de los principios por los que se luchaba en una y otra zona, como el necesario apoyo internacional para ganar la guerra. Ejemplos de esto po-

2 Este trabajo se acompaña de un Anexo de Testimonios en donde se recogen los recuerdos de tres "niños de la guerra". A ellos remitimos a lo largo del texto para ilustrar lo que comentamos en el mismo. Véase en este caso el testimonio de DaLIA Sanz. 
demos verlos en folletos, carteles y publicaciones periódicas aparecidos en españa y en el extranjero. Así, la portada del número 1 (10 de mayo de 1937) de AYUDA. Órgano de la Solidaridad (edición especial para el Norte y Euzkadi), editado por Socorro Rojo Internacional (SRI), recogía la imagen dramática de una mujer con una niña en los brazos. Acompañaba un comentario en el que se alentaba a los hombres a cexterminar a los asesinos que quieren la muerte de vuestras mujeres y de vuestros hijos" ${ }^{3}$.

Donde claramente se puede ver la politización que sufrió la vida infantil fue en el ámbito de la educación. El objetivo era adoctrinar a los niños en los principios contrapuestos por los que se luchaba, a la vez que había que preservarles de las influencias "malsanas" y "subversivas" del contrario. Esto explica las tempranas medidas de depuración que se establecieron y que afectaron a toda la vida escolar, una depuración no sólo punitiva, sino también preventiva puesto que a su través se debía trazar el camino para esa formación ideológica de los pequeños. Ejemplo de ella fueron la incautación y destrucción, en especial en la zona bajo control de los sublevados, de libros y otros materiales procedentes de bibliotecas, ateneos o escuelas. En la parte controlada por los militares franquistas los principios que guiaron la renovación pedagógica fueron los de la defensa del integrismo católico y de la unidad nacional en el seno de una sociedad en la que cada clase social tenia una determinada función que cumplir. Esto tuvo su reflejo en una serie de disposiciones legislativas que anulaban toda la reforma educativa emprendida en el Primer Bienio y retomada por el Frente Popular. Paralelamente se procedía a la construcción de un nuevo orden escolar en el que la Iglesia desempeñó un papel primordial.

En la zona republicana la doble consigna que orientó la politica educativa fue la de "la educación hace libre y dignifica a la persona" y "el derecho de toda persona a la educación y a la cultura sin distinciones". En la evolución de la política educativa republicana se perfilan dos etapas. Una primera, entre septiembre de 1936 y marzo de 1938 , en la que el comunista Jesús Hernández ocupó el Ministerio de Instrucción Pública, y una segunda con el nombramiento, el 5 de abril de 1938, del albañil anarquista Segundo Blanco. El periodo de Hernández se caracterizó por la supeditación de toda la actividad pedagógica a unos principios políticos. La escuela soviética fue el modelo que sirvió para trazar el Plan de Estudios de la Escuela Primaria y la Cartilla Escolar Antifascista, el compedio de todo un programa de for-

Archivo de la Guerra Civil, Salamanca, PER 71. 
mación política. La Cartilla editada por el Ministerio fue texto oficial en todas las escuelas públicas ${ }^{4}$. Se abria con unas instruciones dirigidas a los maestros en las que se explicaba el método seguido:

En esta cartilla (...) se ha aplicado un método lógico y rápido para aprender al mismo tiempo a leer y escribir (...). Cada ejercicio comienza con una frase que luego se analiza y descompone en sus silabas y letras. Estos elementos se utilizan después para formar nuevas palabras y frases. Hemos procurado que todas las frases consignadas tengan un contenido a tono con la lucha heróica que está sosteniendo el pueblo español contra los traidores de España, aliados a los invasores extranjeros. La lucha por la cultura del pueblo español, que la reacción mantenía en la ignorancia y el analfabetismo, va unida inseparablemente a la lucha ideológica y política contra el fascismo. El pueblo español está derrotando al fascismo con las armas en la mano. Los maestros y todos los trabajadores de la cultura deben hacer honor a este ejemplo derrotandio también al fascismo con los libros y la pluma.

Algunos ejemplos de estas frases:

República Democrática

Todo para el pueblo

Gobierno del pueblo

Proletarios de todos los países, unios

El comisario político nos orienta

Lucharemos por nuestra cultura

El Frente Popular nos lleva al triunto

Trabajemos para la guerra

La Unión Soviética nos ayuda

La mujer se emancipa luchando y trabajando junto al hombre

Después de vencer al fascismo tendremos una España próspera y feliz

Con los libertarios al frente del Ministerio se produjo un cambio en esta política acorde con su propia visión de la realidad. Pensaban que no se debía reproducir en los niños el odio y la crueldad de la guerra. Ellos tenían derecho a disfrutar de un mundo propio, solidario, alegre, en armonia con la naturaleza, donde pudieran jugar y sentirse seguros. Esta consideración del mundo de la infancia impregnó la política educativa y se puede ver reflejada en carteles y publicaciones infantiles. Dos ejemplos de carteles. Uno de Moliné, editado por el Consejo Regional de Solidaridad Internacional Antifascista (SIA) de Cataluña con motivo de la celebración de la semana del niño (1-7 de enero de 1938), recoge las figuras de un niño y de una niña rodeados de árboles, pájaros, agua; la niña con una muñeca y el niño con un libro tirando de un caballito, junto a ellos un balón. Otro cartel anónimo editado por las Juventudes

4 Cartilla Escolar Antifascista, Ministerio de Instrucción Pública, 1937. Archivo de la Guerra Civil, Salamanca. Folleto 1.285. 
Libertarias-Federación Anarquista lbérica (JJLL-FAI) muestra una mano adulta que señala varias camisas de los uniformes que llevaban los miembros juveniles de distintos partidos, a un niño que las mira con cara llorosa y amedrentada. Bajo esta imagen que por si misma ya es suficientemente explícita, el lema "No enveneneis a la infancia", llamada de alerta contra la excesiva politización de la infancia ${ }^{5}$. Un último ejemplo lo podemos ver en la revista infantil libertaria Porvenir ${ }^{6}$, didáctica, amena, con historias ingenuas e instructivas para los niños de toda época y país, alegre en la presentación y en la que la guerra y la desunión estaban completamente ausentes. El número 11 es el único que no trae en su portada dibujos alusivos a temas infantiles. La forman siete fotos superpuestas con imágenes de actividades escolares, enmarcadas por un texto que es todo un canto a lo que debe ser la escuela:
La Escuela es la casa de todo los niños
De todas las personas que quieran ser verdaderamente personas
En la escuela se vive y se aprende verdaderamente a vivir
Jugar, reir, trabajar, estudiar, vivir
Niños que juegan, niños que cantan y danzan, niños que estudian, que trabajan. Eso es la vida de la Escuela
Yo sé un himno muy bonito que comienza así:
¡Loor a la Escuela!... ¡Loor al saber!

Las consecuencias de una guerra en la demografía de un país no sólo tienen su reflejo en las muertes violentas ocasionadas por las operaciones militares, los accidentes o la represión. La guerra lleva consigo otros azotes que inciden fuertemente en la población civil. El hambre, la falta de higiene, de atención sanitaria, las enfermedades; son plagas que afectan sobre todo a los niños. Si aceptamos las cifras que da Ramón Salas Larrazabal, murieron 138.030 niños más de lo que se podía prever en una situación de paz, pero es que además la lógica caida de la natalidad produjo 557.185 nacimientos menos de los esperados. Si comparamos ambas cifras con la de 275.000 adultos que murieron de manera violenta, podemos hacernos una idea del fuerte impacto que tuvo la guerra sobre la población infantil. A esto debemos unir los traumas psicológicos que sufrieron muchos de los niños y niñas, las secuelas de los accidentes bélicos y las enfermedades contraídas por la carencia de lo más elemental. Todo ello

\footnotetext{
Ambos carteles se conservan en la colección FIEHS-CEHI, (Centro de Estudios Históricos Internacionales), Barcelona.

6 Porvenir, editada por la FRER, Barcelona, 1937-1938. Archivo de la Guerra Civil, Salamanca. Rev. 183/11. Para una profundización en este tema véase: Fernández SORIA, JuAN MANuEL: Cultura y libertad. La educación en las Juventudes Libertarias (1936-1939). Valencia, Universitat de València, 1996. En especial la tercera parte: «Planteamientos socioeducativos», pp. 263-343.
} 
afectó en mayor grado a los menores de la zona republicana obligados, por la propia evolución de la guerra, a continuos desplazamientos a otras zonas del país o a la evacuación al extranjero?.

Desde el principio de la guerra las ofensivas del ejército de Franco llevaron a un repliegue contínuo de unidades militares republicanas y de contingentes de población civil a zonas todavía controladas por el gobierno de la República. Las consecuencias de estos movimientos de población los sufrieron en mayor medida las mujeres y los hijos de los combatientes. En los grandes núcleos urbanos de Madrid, Valencia y Barcelona se habilitaron refugios para acogerles sostenidos por asociaciones humanitarias o por aquéllas creadas por los propios grupos políticos y sindicales. También desde los primeros días se empezaron a producir contingentes migratorios. Al margen de quienes se evadian por barco y que normalmente se dirigian a Hispanoamérica, las gentes que huian de una u otra zona atravesaban la frontera con Francia y Portugal, siendo repatriadas en su mayoría poco después a la zona de su elección. A mediados de agosto llegaron a Portugal más de un millar de personas con motivo de la toma de Badajoz por las tropas del Ejército de África al mando del General Yagüe y que fue seguida de una fuerte represión.

La primera salida de población hacia la frontera con Francia se produjo a fines de agosto de 1936 con el inicio de la batalla final de Irún. Eran en su mayoría mujeres, niños y ancianos. En octubre de 1936 al comenzar el asedio de Madrid, se creó, por un decreto de la Presidencia de la República, un Comité de Refugiados integrado por distintas instituciones y partidos políticos, con la misión de organizar la evacuación de población civil. Esta primera evacuación desde Madrid se dirigió hacia zonas de Levante. Unos niños iban con sus madres, hermanos, abuelos..., pero otros ya partían solos al cuidado de miembros de distintos organismos de ayuda. Los viajes se hacían en trenes y camiones y resultaban especialmente largos $\left(12,14\right.$ horas), incómodos y peligrosos por los continuos bombardeos ${ }^{8}$.

Las sucesivas derrotas que a lo largo de 1937 sufrió el ejército republicano, sobre todo en el frente norte, condujeron a evacuaciones masivas de niños procedentes de diferentes lugares de España tanto a la región mediterránea de Levante y Cataluña como al extranjero. Con el fin de canalizar todos los problemas derivados de la evacuación, el Ministerio de Instrucción Publica creó, en el mes de marzo, la Delegación Central de

\footnotetext{
"El mito del millón de muertos. Demografía contra leyenda", en Camino para la paz. Los historiadores y la guerra civil, Madrid, Urbión, 1979, págs. 256 y ss.

a Véase el testimonio de JuAn ANTONio MONSALVE.
} 
Colonias que contemplaba todos los aspectos del proceso desde la salida de los niños de los puntos de origen, hasta su instalación en colonias colectivas o en régimen familiar en los lugares de acogida, así como las cuestiones derivadas de su necesario mantenimiento y educación.

En septiembre de 1937 Regina Lago ${ }^{9}$ daba cuenta del número de colonias escolares que habia en esos momentos en España:

\begin{tabular}{llll} 
Colonias colectivas: & 158 & Niños: & 12.125 \\
En régimen familiar: & 406 & Niños: & 33.123 \\
\hline Total: & 564 & 45.248
\end{tabular}

De acuerdo con un informe del Ministerio de Instrucción Publica, en diciembre de 1937, 170 colonias colectivas acogían a 16.953 niños en zonas de Levante (Valencia, Castellón, Alicante y Murcia), Aragón, Cuenca, Albacete y Cataluña. En esta última región L'Ajut Infantil de Reraguarda dependiente de la Generalitat se encargó de todo lo referente a la evacuación. Con ella colaboraban otras instituciones como Segell Pro Infancia - Refugi de Neus Salvador Seguí. Con el fin de coordinar más eficazmente la labor de evacuación, debido al número cada vez mayor de niños que había que atender y a la gran diversidad de instituciones que se ocupaban de ellos, se creó el 28 de agosto de 1937 el Consejo Nacional de la Infancia Evacuada dependiente del ahora denominado Ministerio de Instrucción Pública y Sanidad. Una Delegación del mismo con sede en París se ocupaba de todo lo relativo a los niños evacuados al extranjero.

Como ya señalamos, los niños acogidos en colonias lo fueron en régimen familiar o colectivo. En las primeras los niños residian en familias, pero mantenían una relación estrecha con los maestros responsables del grupo al que pertenecian. Ellos eran los encargados de vigilar su estancia familiar y de que fueran atendidas sus necesidades educativas. La mayor implantación de esta modalidad se debió a los problemas que planteaba la organización de colonias colectivas. Estas últimas estuvieron instaladas en hoteles, palacetes, casas de campo y otros edificios cedidos por sus propietarios o requisados. Normalmente tenían huerta y jardín y se procuró crear en su interior ese calor de hogar del que tan necesitados estaban los niños. Cada colonia tenía un director responsable, varios maestros y

9 Era la encargada de la sección “Organización del régimen pedagógico" de la Delegación Central de Colonias. En una reunión convocada por SRI explicó la labor del Ministerio en relación con las evacuaciones de niños y aportó las cifras que mencionamos a continuación. Véase El Magisterio Español de 15 de septiembre de 1937. 
personal auxiliar. Al margen de esto, la vida interna de la colonia y la formación que recibían los niños era muy diversa dependiendo de los organismos que la sostenían y de los lugares de asentamiento (Levante, Cataluña, Francia o la URSS por ejemplo). En este campo de ayuda a la evacuación e instalación de los niños en colonias destacaron las organizaciones mencionadas de SRI (comunistas) y SIA (anarquistas). Las colonias fueron buenos laboratorios para poner en marcha proyectos de renovación pedagógica, así como para el adoctrinamiento de los niños. Aquí también se dio el contraste, ya aludido, entre la política auspiciada por el Ministerio de Hernández y la que mantenían los libertarios contrarios a que los niños participaran del entrentamiento ideológico de la guerra.

A la vez que se producía este asentamiento de niños en colonias en diversos puntos de la España republicana, a lo largo de 1937 se organizaron una serie de expediciones hacia varios paises. En unos casos fueron los gobiernos los que se ofrecieron a acogerles, pero la ayuda vino en gran medida de asociaciones humanitarias, grupos religiosos (los cuáqueros) y organismos políticos y sindicales apoyados en cada caso por amplios sectores de la opinión pública. La ofensiva del ejército de Franco sobre el frente norte en la primavera de 1937 con los continuos bombardeos y bloqueo de las poblaciones aceleró el proceso de las evacuaciones. Como recuerda Alberto Onaindia ${ }^{10}$ :

Era tanto el horror que causaban, sobre todo en los ancianos, mujeres y niños, estos bombardeos aéreos contra ciudades abiertas, que los padres de familia demandaban y urgian a las autoridades del Gobierno de Euzkadi adoptar una politica de evacuación, con el fin de poder salvar la vida de los no combatientes.

Los bombardeos de las ciudades vascas en la primavera de 1937, en especial de Guernica el 26 de abril, atrajeron la atención de la opinión pública internacional en la que empezó a calar el lema insistentemente repetido entonces de "Ayudad a los niños de España". Así, en colaboración con la política que el gobierno de la República y los gobiernos autónomos vasco y catalán desarrollaban en este ámbito, se crearon comités de ayuda en distintos países. Uno de éstos fue el "Comité d'Accueil aux Enfants d'Espagne» con sede en París. El Comité se creó por iniciativa de la Confédération Générale du Travail y tuvo sus primeras reuniones en noviembre de 1936. Actuaba en contacto con el gobierno español y atendía a los niños desde el punto de

10 En Hombre de paz en la guerra, Buenos Aires, Ekin, 1973, pàg. 284. Reproducido por Gregorio Arrien, Niños vascos evacuados a Gran Bretaña (1937-1940), pág. 38. 
partida hasta el lugar de destino. Los niños iban en grupos acompañados por maestras y personal auxiliar. El primer destino eran los campos de selección (camps de triage) donde se les distribuía para su posterior emplazamiento en familias o en colonias colectivas. También servian para acoger a los niños en tránsito hacia otros países como Bélgica o Suiza.

En colaboración con el gobierno autónomo de Euzkadi, el Comité participó en sucesivas evacuaciones de niños vascos entre marzo y octubre de 1937 desde los puertos de Santurce y Bilbao y, tras la caida de esta cludad, desde Santander. Una primera expedición fue la que se organizó en marzo de 1937 en la que 450 niños vascos fueron alojados en la colonia "Casa Dichosa" de la isla de Olerón en Francia. En los meses siguientes fueron varias las expediciones de niños procedentes de distintas zonas de la España republicana a Francia, que fue el país que acogió en todo momento un mayor número de refugiados españoles y entre ellos de niños. Además de Francia otros países recibieron a niños refugiados. El 21 de mayo de 1937 partió del puerto de Santurce una expedición a Gran Bretaña integrada por cerca de 4.000 niños vascos. Para acogerlos se creó el «Basque Children's Comittee» presidido por la duquesa de Atholl. También a Bélgica, Dinamarca, Holanda y Suiza fueron niños. A Bégica llegaron en sucesivas expediciones unos 3.200. Dinamarca sostuvo 102 niños en dos colonias, Holanda acogió a 195 y Suiza, a 245 niños en régimen familiar. Otros países como fue el caso de Suecia sostuvieron varias colonias en suelo francés.

Junto a estas expediciones especificas organizadas por el gobierno autónomo vasco y motivadas por la caída del frente norte, se llevaron a cabo otras evacuaciones de niños procedentes de distintos puntos de España y también de Euzkadi. A la Unión Soviética fueron cerca de 3.000 repartidos en cuatro expediciones. La primera salió de Valencia el 21 de marzo de 1937 con 72 niños de los que 50 procedian de Madrid. En agosto inauguraban la primera Casa de Niños Españoles en Moscú. La segunda expedición partió del puerto de Santurce el 13 de junio. La formaban 1.495 niños en gran parte vascos. La tercera salió del puerto de El Musel (Gijón) el 24 de septiembre con 1.100 niños, casi todos asturianos, vascos y santanderinos que estaban alojados en orfanatos. La evacuación de estos niños fue organizada por la Consejería de Instrucción Publica del Consejo de Asturias y León. Una cuarta se formó a finales de octubre de $1938 \mathrm{con}$ 300 niños procedentes de Aragón y de la zona mediterránea.

Una última expedición a la que vamos a referirnos es la de los llamados «niños de Morelia». Constituyeron el primer contingente de refugiados que llegó a México. Con el apoyo del gobierno presidido por Lázaro Cárdenas 
se habia formado a principios de 1937 un Comité de Ayuda a los Niños del Pueblo Español. Este Comité ofreció al gobierno republicano acoger y educar a unos 500 niños mientras en España continuara la guerra. En total fueron 456 niños procedentes en una gran parte de Barcelona y de Madrid. La expedición embarcó el 25 de mayo en el trasatlántico Mexique, llegando el 7 de junio a Veracruz. Fueron trasladados a Morelia (en el estado de Michoacán) donde el gobierno habia organizado en régimen de internado la escuela "España-México». En ella ingresaron 442 menores, de los que 157 eran niñas y 285 niños.

El continuo avance del ejército de Franco a lo largo de 1938 fue agravando el problema de las evacuaciones. Las caídas de los distintos frentes replegaban a grandes contingentes de población hacia un territorio en poder del gobierno de la República cada vez más menguado. Estas continuas oleadas de refugiados desbordaban todas la previsiones en cuanto a acogida e instalación y, como es lógico, afectó duramente a los niños. Muchas colonias de Levante y Cataluña tuvieron que convertirse en meros refugios donde el hacinamiento de sus moradores impedía desarrollar la labor asistencial y educativa para la que habian sido proyectadas. Por otra parte, en las ciudades y sobre todo en Barcelona, se endurecieron las condiciones de vida, lo que se tradujo en un considerable aumento de las enfermedades infantiles.

En esta situación crítica las Brigadas Internacionales habían creado en Barcelona un Comité pro-niños españoles que, entre sus actividades, estaba la de sostener comedores infantiles. Como recuerda una doctora que acompañaba a las Brigadas ${ }^{11}$ :

... hemos visto que hay miles y miles de niños españoles que sufren tanto por los bombardeos como por las privaciones. Sobre todo los pequeños que han perdido sus familias y sus hogares y que se ven en el trance de vivir en casa de refugiados, están a menudo enfermos por falta de comida y de higiene. Nosotros, los médicos, hemos organizado ambulatorios para los niños en todos los Centros en que trabajamos y los vacunamos para protegerlos de las enfermedades infecciosas y los curamos de las afecciones de la piel, de los oidos y dientes, etc. Cuando vamos por las calles y vemos a uno de nuestros pequeños clientes con sus ojos brillantes, libres ya de toda inflamación y su brazo levantado para el "Salud", nos sentimos felices de haber ayudado a un futuro ciudadano de la España libre.

Con la caída de Barcelona se inició el éxodo que en pocas semanas llevó a cerca de medio millón de españoles a Francia. Siguiendo a Javier

1 Testimonio recogido por Teresa Pamies, Los niños de la guerra, Barcelona, Bruguera, 1977. pág. 80 . 
Rubio, el número de personas que se expatriaron como consecuencia de la guerra civil fue el siguiente ${ }^{12}$.

Campaña de Guipúzcoa

Evacuación del norte en 1937

Evacuación del alto Aragón en 1938

Exodo desde Cataluña en 1939

Fugitivos de la zona centro-sur al final de la guerra

Total
15.000

160.000

24.000

470.000

15.000

De los refugiados que pasaron a Francia unos 170.000 eran mujeres, niños y ancianos (a primeros de marzo de 1939). De otro lado, en ningún momento se produjo la existencia simultánea de esa cifra global de refugiados, pues las repatriaciones fueron constantes. Entre el 1 y el 19 de febrero de 1939 volvieron por Irún 1.114 niños y las repatriaciones en masa desde Francia empezaron poco después de terminar la guerra civil. En agosto de 1939 ya habian regresado unas 250.000 personas, de las que una mayoría eran mujeres y niños. Los primeros momentos en Francia fueron muy difíciles no sólo por las condiciones materiales de la acogida, sino también por el rechazo de los sectores más conservadores de la opinión pública hacia los «rojos» españoles. Hubo mujeres y niños en los campos de internamiento como fue el caso del campo de Argelès, pero la mayor parte fueron distribuidos, desde los campos de selección, a distintos puntos del país donde eran acogidos en improvisados refugios. Muy pronto, sin embargo, se verían inmersos en otra guerra y obligados una vez más a huir bajo los bombardeos y a sufrir las privaciones que toda guerra lleva consigo ${ }^{13}$.

Aunque el Gobierno de Franco supeditó, en las semanas siguientes a la finalización de la guerra, el retorno de los refugiados desde Francia a los acuerdos que estaba negociando con el gobierno francés, lo cierto es que con respecto a los niños habia mostrado un extraordinario celo para su repatriación, ya desde el mismo momento en que tuvo conocimiento de las primeras expatriaciones en 1937. Así, paralelamente al «Basque

:2 En La emigración de la Guerra Civil de 1936-1939. Madrid, Editorial San Martín, vol. I, pág. 106. Véase tambièn su trabajo: "Flux et permanences", en MILzA, P. y PESCHANSKI, D., Exils et Migration. Italiens et Espagnols en France, 1938-1946. Paris, Editions L'Harmattan. 1994, págs. $35-45$.

i3 Véanse los testimonios de Dalia Sanz y de Juan Antonio Monsalve. 
Children's Committee" de la duquesa de Atholl, el gobierno franquista apoyó al "Spanish Children Repatriation Committee» presidido por el Duque de Wellington. Con el fin de encauzar todo lo relativo a las repatriaciones se había creado en 1937 la Delegación Extraordinaria de Repatriación de Menores dependiente de la Delegación Nacional del Servicio Exterior de FET y de las JONS. Su objetivo era localizar a todos los niños y niñas expatriados y procurar su retorno a España, pero en esta tarea tropezo con grandes obstáculos debido principalmente al rechazo de padres y familiares directos para hacer la oportuna solicitud de reclamación, así como a las trabas que pusieron los gobiernos de algunos países y la propia colonia de refugiados españoles residente en ellos. Según un informe sobre la labor desarrollada por la Delegación de Repatriación de Menores, a la altura de noviembre de 1949 el número global de niños y niñas que habian sido expatriados alcanzaba la cifra de 32.037. En cuanto a las repatriaciones "perfectamente controladas" por la Delegación ascendían a 20.266. El desglose de estas cantidades por países es el siguiente ${ }^{14}$ :

\begin{tabular}{|c|c|c|c|}
\hline Paises & Expatriados & & Repatriados \\
\hline Francia & 17.489 & & 12.831 \\
\hline Bélgica & 5.130 & & 3.798 \\
\hline Inglaterra & 4.435 & & 2.822 \\
\hline Rusia & 3.291 & & 34 \\
\hline Suiza & 807 & & 643 \\
\hline México & 430 & & 56 \\
\hline Territorios franceses & & Orán & 23 \\
\hline Norte de África & 335 & Casablanca & 1 \\
\hline Dinamarca & 120 & & 58 \\
\hline rotal & 32.037 & & 20.266 \\
\hline
\end{tabular}

Los niños y niñas que retornaron a España recien terminada la guerra civil se encontraron con un mundo muy diferente al que habían dejado al marcharse. Siempre arrastraron el estigma de ser hijos de "rojos" y sufrieron discriminaciones y rechazos por ello. A esto se unió el desamparo

14 Archivo General de la Administración. Sección Presidencia de Gobierno. S 911.245/9. Agradezco a Miguel. ÁNGel VILlanueva ei que me haya proporcionado una copia del documento, asi como sus observaciones sobre este tema de los "niños de la guerra". 
de muchos por haber perdido a sus padres o por estar éstos represaliados. Hubo el caso de niños que, cuando estalló la guerra, fueron dejados por sus padres al cuidado de familiares, reencontrándose después en el exilio. También la infancia y adolescencia de estos niños quedó marcada primero por haber sido "abandonados" y después porque se vieron obligados a iniciar una nueva vida en otro país.

Las evacuaciones de niños al extranjero durante la guerra se habian concebido con un carácter temporal. Al cambiar la situación, regresarían a España. En este sentido, hubo paises como Francia, Inglaterra o Bélgica que facilitaron el retorno. No fue el caso de México y de la URSS, paises que no reconocieron al gobierno de Franco. De los niños de Morelia sólo regresaron 61 . Hubo presiones por parte de los refugiados españoles allí asentados para evitar este regreso y tampoco el gobierno mexicano se mostró muy predispuesto al mismo. Esto, sin embargo, no se contrapesó con una fácil integración de los niños. La mayoría sufrieron grandes dificultades para adaptarse a la vida en México. Tampoco en el caso de los niños y niñas evacuados a la URSS los españoles allí residentes, muchos de los cuales eran dirigentes del Partido Comunista Español, facilitaron el retorno a lo que se unió la actitud contraria del gobierno ruso. Sólo tras la muerte de Stalin, en marzo de 1953, se iniciaron las negociaciones con el gobierno español para el regreso a España o para la repatriación definitiva. La primera expedición vino en 1956. Entre los puntos de negociación entre ambos gobiernos estaba el que no fueran considerados por el régimen de Franco como exiliados políticos, puesto que no habian luchado en la guerra civil. Muchos de estos niños se integraron en la sociedad soviética como profesionales cualificados, pero hubo bastantes casos de inadaptación y de claro rechazo hacia la sociedad de acogida.

Exilio o retorno, lo cierto es que hubo una generación a la que la guerra marcó de forma indeleble. Es también evidente que los hijos de los perdedores fueron los más perjudicados porque debieron sufrir las consecuencias de la derrota sin comprender el porqué de una guerra ni haber participado para nada en ella. Los niños que no fueron repatriados tuvieron que asumir, no teniendo clara conciencia de ello, la condición de exiliados. Como Dorothy Legarreta demuestra en el caso de los niños vascos, pero extensible al conjunto de los niños evacuados ${ }^{15}$, los más perjudicados por la separación fueron los chicos de más de diez años. Estos pre-adoles-

15 Véase: The Guernica Generations. Basque Refugee Children of the Spanish Civil War, en especial capitulos 8 y 9 , pp. $241-333$. 
centes o adolescentes tuvieron grandes problemas para adaptarse en el país de acogida, sobre todo en el caso de las colonias de la URSS y también en México donde se produjo en muchos casos una dicotomía entre las políticas oficiales de los gobiernos y las actitudes de los ciudadanos hacia los refugiados. Con todo, la mayor parte de los niños y niñas que no volvieron, acabaron integrándose en el país de acogida, aprendieron la lengua, fueron a la escuela y formaron un nuevo hogar. Los que ya adultos vinieron a España buscaron en su mundo de infancia aquellos elementos que les ayudaran a identificar sus raíces. Eran los juguetes: tebeos, muñecas, soldaditos, recortables... que dejaron cuando debieron partir. Algunos de estos «niños de la guerra» se quedaron, otros continuan viviendo en el país de acogida porque en él ha transcurrido casi toda su vida y porque allí están sus hijos y sus nietos que se sienten ciudadanos de ese país.

\section{SELECCIÓN BIBLIOGRÁFICA}

ALONSO, J.: "La historiografia sobre los niños del exilio: la historia olvidada", Exils et migrations ibériques au xxe siècle, París, 3, 1997

ALONSO, J. y MAYORAL, M.: "La repatriación de "los niños del exilio": un intento de afirmación del régimen franquista", en TUSELL, J. ALTED, A. y MATEOS, A. (EDS.): El régimen de Franco (1936-1975), Madrid, UNED, 1993, tomo I.

ARRIEN, G.: La generación del exilio. Génesis de las escuelas vascas y las colonias escolares (1932-1940), Bilbao, Onura, 1983.

ArRIEN, G.: Niños vascos evacuados en 1937. Álbum histórico, Cajas de Ahorro de Vizcaya, Guipúzcoa y Álava, 1988.

ARrien, G.: Niños vascos evacuados a Gran Bretaña (1937-1940). Cajas de Ahorro de Vizcaya, Guipúzcoa y Álava, 1991.

BELL, A.: Only for three months. The basque children in exile. Norwich, Mousehold Press, 1996.

BERGER, G.: Les enfants de la guerre civile espagnole. Travail de fin d'études. École d'interprètes internationaux, Universite de Mons, 1991.

BUChANAN, T.: "The role of the British Labour Movement in the origins and work of the Basque Children's Committee, 1937-1939". European History Quartely, vol. 18, 1988.

Conde Magdaleno, P.: Por qué huyen en baúles..", Buenos Aires, (s.e.), 1951.

DELMONT, L.: Los niños de la guerra: un aspect méconnu de l'emigration espagnole en URSS. Travail de fin d'études. École d'interprètes internationaux, Université de Mons, 1991

Duroux, R: "Historia y desmemoria. Prácticas culturales en los refugios de mujeres españolas en Francia, 1939-1940, en Mélanges Louis Cardaillac, Zaghouan, FTERSI, abril de 1995.

Duroux, R. y THIERCELIN, R.: "Los niños del exilio: asignatura pendiente", en CuESTA, B. y BERMEJO B. (coordinadores): Emigración y exilio. Españoles en Francia, 1936-1946, Madrid, Eudema, 1996. pp. 167-182.

FERnANDEZ SORIA, J. M.: "La asistencia a la infancia en la guerra civil. Las colonias escolares", Madrid, Revista de Historia de la Educación, 6, 1987.

FOULKES, V.: Los niños de Morelia y la escuela España-México: Consideraciones analiticas sobre un experimento social, México, UNAM, 1953.

L'HEBERGEMENT des enfants de la guerre d'Espagne en Belgique, Bruxelles, Federación de Asociaciones de Enseñanza y Centros Españoles en Bélgica, (s.f. 1992).

Labajos-PÉrez, E. y Vitoria-Garcia, F.: Los niños. Histoire d'enfants de la Guerre civile espagnoles réfugiés en Belgique (1936-1939). Erpent-Bruxelles, Association "Los niños de la guerra". Editions Vie Ouvrière, 1994.

LegarRetA, D.: The Guernica Generation. Basque Refugee Children of the Spanish Civil War, Reno, University of Nevada, 1984. 
Maroues, P.: Les enfants espagnols réfugiés en France (1936-1939), Paris, AutoEdition, 1993. "Niños alicantinos en la URSS", en Alicantinos en el exilio. Alicante, Monográfico de Canalobre. Revista del Instituto de Cultura Juan Gil Albert, 20/21, 1991.

PAMIES, T.: Los niños de la guerra, Barcelona, Bruguera, 1977.

Pla Brugat, D.: Los niños de Morelia, México, INAH, 1985.

RuBIo, J.: La emigración republicana de la guerra civil de 1936-1939. Madrid, Editorial San Martín, 1977, 3 vols.

TIANA FERRER, A.: Educación libertaria y revolución social (España, 1936-1939). Madrid, UNED, 1987 ("Las colonias para niños refugiados").

Zafra, E., Crego, R. y Heredia, C.: Los niños españoles evacuados a la URSS (1937), Madrid, Ediciones de la Torre, 1989.

\section{TESTIMONIOS}

Los tres testimonios que aparecen a continuación fueron recogidos en el marco de un proyecto de realización de un documental sobre los refugiados españoles en el Mediodía de Francia. Este proyecto corrió a cargo de un equipo de profesores y técnicos bajo el patrocinio de la UNED, la Universidad de Toulouse-Le Mirail y el Ministerio de Cultura español. Entre octubre de 1991 y junio de 1993 se realizaron los viajes de localización y grabación audiovisual. Se filmaron un total de 50 horas de testimonios, fotografias, procedentes en su mayor parte de los archivos personales de los entrevistados, así como objetos y lugares de memoria vinculados a la historia del exilio. El eje geográfico fue la ciudad de Toulouse considerada como la capital del exilio español de 1939 en Francia. La película está editada por el Servicio de Publicaciones de la UNED junto con un libro en el que se exponen los planteamientos metodológicos y técnicos subyacentes en la realización del documental, a la vez que se hace una contextualización histórica que facilita su comprensión, en especial de cara a la posible utilización por estudiantes.

Los testimonios seleccionados pertenecen a tres niños de la guerra: Dalia Sanz (París, 1928), Juan Antonio Monsalve (Madrid, 1925) y Floreal Samitier (Zuera-Zaragoza, 1934). Cada uno de ellos constituye un ejemplo de las plurales y diferentes trayectorias de exilio a las que obligó la guerra civil y por la sencillez y realismo con el que están evocadas las vivencias, hablan por si mismos. No obstante, hay una diferente percepción de la realidad reflejada por los testimonios de Dalia Sanz y de Juan Antonio Monsalve en relación con el de Floreal Samitier. Mientras que los dos primeros se centran en el relato de los hechos en los que se vieron inmersos, el de Samitier se construye como interrogante en torno al problema de la identidad. Los tres "niños de la República» se educaron en el seno de familias militantes de grupos de la izquierda (Confederación Nacional del Trabajo - anarquista- y Partido 
Comunista). Dos de ellos pasaron la frontera con sus madres y hermanos. El tercero se quedó en España cuando estalló la guerra al cuidado de unos familiares. Tenía dos años. Se reencontró con sus padres en Francia a la edad de 14 años. De Monsalve y Samitier he escogido dos fragmentos, alusivos a los temas aquí abordados, de sendas entrevistas realizadas en mayo de 1992 y que se conservan grabadas en vídeo. La transcripción que se hace es literal. De Dalia Sanz reproduzco el testimonio escrito que me entregó cuando fuimos a entrevistarla a Béziers en junio de 1993.

\section{DALIA SANZ}

Me llamo Dalia Sanz Sanchez. Naci en París el 13 de junio de 1928. Mi padre era un militante libertario. Cuando en 1931 la República fue proclamada, mis padres volvieron a Madrid donde nació mi hermano Delio en el mismo año, en el año 1935 nació mi hermano Eliseo.

Cuando estalló el movimiento en 1936, estábamos todos en el pueblo de mi padre en Fuembellida, provincia de Guadalajara, y de noche, recuerdo, nos fuimos todos a pie y salimos hacia la provincia de Albacete, a Almansa, donde estaban la hermana de mi madre y mis abuelos, que todos ellos volvieron a España en 1931 como mis padres. Mi padre y su hermano más joven, Primitivo, que marchó con nosotros, se fueron voluntarios para el frente en la Columna del Rosal, es una referencia que me quedó desde niña. A los tres meses [mi padre] murió combatiendo en el frente de Belchite. Mi tío Primitivo lo presenció. Mi padre era un hombre que le gustaban mucho los libros. Poseía la Enciclopedia de Eliseo Reclus, entre otros, también recuerdo un libro donde me hacía ver las cinco partes del mundo.

Mi madre en Almansa ayudaba en un hospital y también militaba. Un dia mi tía Consuelo volvió desde Barcelona y dijo a mi madre que inmediatamente teniamos que salir, pues las tropas de Franco iban a cortar la carretera de Valencia a Barcelona. Las dos nos cogieron a los tres niños y como pudimos fuimos hasta Valencia, donde esperamos un camión que finalmente nos pudo llevar. Cuando clareó el día dábamos vueltas subiendo a una montaña. Fuimos bombardeados, nos apeamos del camión, finalmente llegamos a Barcelona. Estuvimos hospedados en un piso en Sans que era de una compañera, María, que estaba en el frente con su marido. Mi madre todos los días salía para hacer trámites, pues un hermano de mi padre que se quedó en Francia, en Crancey (Aube) pequeño pueblo al lado de Romilly-sur-Seine, nos había mandado un certificado para hacerse cargo de nosotros. Era la primavera de 1938, casi todas las noches tocaban las sirenas, Barcelona era bombardeada, mi madre nos vestía y bajá- 
bamos las escaleras, estábamos en el quinto piso, una o dos veces nos llevó al metro, pero nunca a un refugio, nos dijo que un dia presenció que una bomba cayó en la entrada de uno de ellos. Todo era muy difícil, no conociamos a nadie, colas interminables para conseguir algunas avellanas y almendras, la Campsa fue bombardeada, noche y día salia aquel humo inmenso. Después de tres o cuatro meses mi madre me llevaba al colegio racionalista de los Ocaña.

Por fin, yendo a ver a los servicios adecuados, entre ellos a la Federica Montseny, mi madre consiguió el pasaporte y pudimos subir al tren hacia Francia. En Cerbére fuimos acogidos con muchos otros por la Cruz Roja que nos dio de comer. Recuerdo el sabor especial de la leche condensada y el baño que mi madre nos dio en la playa.

Mis tíos de Crancey nos acogieron. Ellos ya tenían dos, María y Lis. Mi madre tuvo que marchar enseguida, pues no tenía papeles para quedarse en Francia. Fue a París donde conocía y buscó trabajo. La guerra estalló en Francia, se perdió, mis tíos y los cinco niños hicimos la retirada unos setenta kilómetros, los alemanes enseguida nos alcanzaron y después de un gran bombardeo nos hicieron volver al pueblo. Fuimos ocupados por las SS en aquel largo invierno del 40, estábamos en la zona ocupada. Cuando mi madre encontró trabajo, pues tuvo también que huir de Paris, se vino a Decazeville donde ella, sus padres y hermana habian vivido y trabajado cuando niños, en Penchot. En 1942, por mediación de la Cruz Roja, pudimos ser trasladados por la zona de demarcación de Crancey a Decazeville donde nos reunimos con mi madre y mi tía Consuelo y tío Pedro, que fueron unos segundos padres para nosotros.

Empecé a trabajar a los catorce años en una COOP, mis hermanos fueron al colegio. Delio entró en la fábrica, trabajaba y aprendía, sacó dos diplomas, "Menuiser Ebaniste» y "Ajusteur». Cuando en el 1950 y 1951 empezó a haber paro y se hablaba de una tercera guerra mundial, el organismo IRO facilitó la salida de Francia a muchos refugiados. Mi hermano Delio se marchó con otros compañeros al Canadá. En el barco cumplió sus 20 años. Mi hermano Eliseo se vino con nosotros para el Brasil. En el 1954 mi madre fue despedida de la fábrica como extranjera y se reunió con nosotros en Puerto Alegre en el 1955, pues ya nuestro hijo Helios tenia dos años.

\section{JUAN ANTONIO MONSALVE}

Yo soy uno de los niños de la guerra civil española que tuve que salir de mi país natal [Madrid] a los alrededores del 4 ó 5 de noviembre de 
1936, consecuencia de que el régimen de Franco y la aviación alemana habian decretado de que Madrid iban a hacer una ciudad rasa. Mi padre que estaba bien emplazado en las milicias y por su actividad política, tuvo la ocasión de hacernos evacuar de Madrid con todos mis hermanos y otros familiares y otros niños y personas de una cierta edad. Nos evacuaron, o mejor dicho nos refugiaron en Mula (Murcia) por razón siguiente de que teníamos familia alli y mi padre aprovechó esta circunstancia (...).

Al salir a los 11 años de mi pueblo natal siendo un niño y cogiendo la responsabilidad de dos hermanos, de una chica y de un chico de edades inferior a la mía, para mi aquello fue una gran responsabilidad y esa responsabilidad la he tenido hasta los 25 años por circunstancias de la guerra.

Mi padre después de las milicias, pues le integraron al servicio de Transmisiones y por estas razones posiblemente estaba enterado de cosas que otros militares o militantes de ciertos partidos lo desconocían, pero él estaba bien introducido y cada vez que podía, pues trataba de ayudarnos en ese sentido de protegernos. Paralelamente mi madre no salió de Madrid con nosotros, se quedó en Madrid puesto que era responsable de un almacén que el Partido Comunista tenía establecido y era responsable del material de ropa, calzado, vivienda, que reagrupaban y lo distribuían gratuitamente para todos aquellos que lo necesitaban, pues que no había venta de ciertos artículos.

Cuando en 1939, en el mes de enero, la aviación alemana "pilonó" [apisonó] Barcelona, cada cuarto de hora venían "pilonando" los bombardeos que venían desde Baleares a descargar sobre Barcelona, empezó ya la evacuación del gobierno republicano hacia la frontera. Mi padre tuvo la oportunidad de hacer venir a mi madre hacia Barcelona, puesto que ella se había quedado en Madrid con otro de mis hermanos, el más pequeño. $Y$ llega el momento ya que en Barcelona había que evacuar y aprovechó de hacernos evacuar con uno de los camiones militares hacia la frontera pasando por Vic y la aviación alemana siguiendo la columna de camiones y los aviones "pilonándonos" detrás. Llegamos a Vic, alli tuvimos que refugiarnos debajo de una arboleda, puesto que alli pensaba que alli ibamos a desaparecer todos de la manera que los camiones volaban y la cantidad de muertos que hubo en aquel momento.

Conseguimos continuar el viaje y llegamos hasta la Junquera y en la Junquera estacionamos allí durante una semana o diez días, poco tiempo, en muy malas condiciones de alojamiento. Cuando mi padre pudo acercarse hacia nosotros llega el momento en que entregó a mi madre un pasaporte que teniamos derecho de irnos hacia México. Llega el momento en que hay que evacuar de nuevo la Junquera y pasamos por le Perthus y 
llegamos a le Boulou. En le Boulou llegamos al anochecer y en la estación de le Boulou, pues un montón de personal de niños, mujeres, ancianos y el resto del ejercito que seguía con los camiones militares y con el armamento recogido por los gendarmes, y los hombres encaminados hacia otros lugares que luego supimos que iban a los campos de Argelès, a los campos de Saint Cyprien, Barcarès.

Nosotros tuvimos la mala suerte de quedarnos alli en le Boulou, hicimos tres noches a cielo raso, nevando, uno de mis hermanos con la tosferina, que pensábamos que le ibamos a dejar en la frontera, tuvo la suerte de poder sobrepasar este "cap" sin ningún tratamiento «medical» y todo esto pasó natural. Yo que era de los mayores de estas tres familias que estábamos juntos, tres mujeres, éramos trece en total, el resto, pues éramos niños, yo el mayor de todos, y yo buscando por un sitio y por otro para suministrarnos alimentación. Los militares lanzaban los chuscos de pan y quien los podía coger, los cogía, y quien no podía, pues no los cogía, y la distribución del agua.

$Y$ llega el momento que, ya al cabo de los tres días recibiendo la nieve con una manta que teníamos, sin ningún impermeable ni nada para podernos abrigar del mal tiempo, veo que en la estación se estaba formando una rama de tren y veo que hay un vagón que estaba completamente vacío. Entonces yo, pues prosiguiendo mi papel de jefe de familia a los 11 años, a mis hermanos y las otras chicas y chicos, hijos de estas compatriotas amigas, los hago subir al vagón y alli, pues a esperar. A una cierta hora de la noche empezamos a sentir el movimiento, la formación del tren, un tamponazo para arriba, un tamponazo para abajo, allí todos alarmados, que hacemos, que bajamos, no bajamos. Aqui nos quedamos. En ese momento, cuando el tren empezó a moverse, el tren se llenó y cogemos el rumbo. El tren se formó, un tren de mercancias, y éramos dos o tres trenes de viajeros. Nuestro tren se llenó y llegamos a aterrizar a Cahors en Lot. Al pasar por Toulouse el tren se paró y la población, que seguramente estaba ya al corriente de este proceso, en la estación una ovación de una parte de la población y dándonos por las ventanillas del vagón pan, alimentos, agua, el poco tiempo que se paró.

Y luego continuó el tren para arriba y llegamos a Cahors, bajamos y la misma operación. Una cantidad de ciudadanos franceses y de otras nacionalidades, los unos por curiosidad, los otros por ansiedad de saber quienes éramos y los otros por solidaridad. Los que eran por solidaridad, pues a darnos pan, chocolate, bebida y todo esto desde la estación de Cahors hasta el cuartel, que habrá aproximadamente un kilómetro y medio, andando y protegidos o acorralados por los gendarmes y los se- 
negaleses. Llegamos al cuartel, nos meten allí en las habitaciones del cuartel y vigilados y guardados por los militares franceses, los gendarmes y los senegaleses. Estuvimos alli durante dos o tres días, la primera noche en el suelo, la segunda noche nos dieron paja para podernos abrigar, estar un poco más suaves para descansar.

Y a los dos o tres días tenemos noticias de que se van a formar autobuses para salir hacia ciertos pueblos del departamento que acogían a los refugiados, que ya nos daban el nombre de refugiados. Tan pronto como llegamos a Cahors, refugiados españoles. Llegamos al pueblo donde nos acogieron, un pueblo limítrofe a la Dordogne, cerca de Cazals, el pueblo se denomina Marminiac. El alcalde de este pueblo fue el autor de nuestra llegada al pueblo, puesto que fue él el que tuvo la buena intención de hacernos venir hacia el pueblo, este hombre con ideas políticas avanzadas.

Los primeros dias fuimos acogidos por la municipalidad, fuimos albergados en las escuelas y fuimos albergados en la propia alcaldía del pueblo. Para alimentarnos nos pusieron los dos restaurantes del pueblo a nuestra disposición, durante una semana o quince días, no creo que fueran más de quince días, puesto que nos albergaban nos dieron un subsidio o ayuda financiera y tratar de hacer una vida normal independientes ya cada uno, o sea de no ir al restaurante.

La población del pueblo venía a vernos a ver si éramos personas normales, porque como se habia escrito tantas cosas en contra de los republicanos españoles consideraban que los republicanos españoles, pues nos comíamos a los niños crudos, que no éramos personas normales, pues en fin, toda una cantidad de infamias que se lanzó contra nosotros. Cuando en el pueblecito aquel, de unos 500 ó 600 habitantes, llegaron a ver nuestro comportamiento sentimos acerca de los más adeptos, los más republicanos y personas de izquierda que se acercaban a nosotros y trataban inmediatamente de aportarnos su ayuda. Paralelamente siempre con la ayuda del alcalde, el cual en una cierta época nos reunió y nos dijo que, para poder tener un buen acogimiento del pueblo, teníamos que tratar de defendernos por nuestros propios medios, puesto que la subvención que nos daban no se podía prolongar, y nos hizo comprender que teníamos que integrarnos y ganarnos la vida como podíamos.

Entonces en este pueblecito llega el momento de la declaración de guerra de 1939, falta mano de obra, puesto que todos los hombres y jóvenes que podían ser enrolados en el frente los movilizaron, y faltaba mano de obra y otra vez de nuevo nos hacen un llamamiento y el alcalde aprovecha diciéndonos: yo os podré ayudar a condición de que os integreis y vayais a ayudar a todo aquél que os necesite, y nos hizo comprender que a las fa- 
milias que él nos resguardó..., puesto que a otros refugiados el alcalde los hizo reintegrar a España, pues no eran personas gratas. $Y$ así llega el momento de que nos vamos integrando a la vida normal.

\section{FLOREAL SAMITIER}

Mi vida empieza como aquel que dice en el 34. Del 34 al 36, siendo crío, no tengo ningún recuerdo. Mis primeros recuerdos son duros puesto que no tengo ninguna referencia familiar directa. A partir de los años 45, 46 tengo las referencias familiares de que mis padres «rojos" no están en España, no están conmigo, no los puedo ver, no los conozco. Hay la referencia familiar de que de alguna manera soy una carga para mis familiares en España con los que estoy, puesto que tienen que atender a un hijo que no es de ellos, hay los roces familiares de reproches que se utilizaban en aquellos momentos y que la propaganda hacia reales sobre los padres que habían abandonado a los hijos en función de unos proyectos o unas espectativas raras que no se explicaban nunca.

Por consiguiente mis primeros recuerdos en la vida han sido siempre de una cosa rara que no estaba en acuerdo con la forma de vivir de los demás chavales de mi edad, que ellos tenían una situación familiar normal. La mía era anormal en todos los sentidos. No era normal hasta el extremo en que yo no llevaba ni mi nombre, puesto que en aquellos momentos Floreal no se podia llevar, mi nombre había desaparecido de los papeles, sin embargo cuando recibia alguna carta de mi padre que decía: "Querido hijo Floreal", pues yo preguntaba quien era aquel Floreal, puesto que no era yo. $Y$ esos primeros recuerdos de mi vida me han marcado profundamente, puesto que en el momento que puedo venir a Francia ya con catorce años, yo no tengo referencia familiar precisa, aparte todo lo que yo he podido oir de un lado y de otro, pero que no corresponde a lo que aquí en Francia decimos "Vécu", inmediato, una serie de referencias raras, imprecisas.

Bueno, pues yo cuando llegué en el tren a la frontera de Port Bou, en mi poco bagaje llevaba medio tomo de El Quijote. Al mismo tiempo llevaba una serie de cromos del fútbol de aquellos tiempos. Lo curioso es que mi padre estaba encantado cuando me vió llegar con El Quijote, pero no lo estaba tanto cuando me vió los cromos, sobre todo que representaban personajes de la época estilo Izaguirre, Gorostiza, Igoa.

Yo cuando me encuentro con mis padres es una situación un poco rara puesto que me dicen: "este es tu padre y esta es tu madre", me tocaron éstos como me habian podido tocar otros, yo no puedo hacer el distingo, se 
hace después más tarde, a la larga, y que en cierto modo algo difícil, puesto que yo ya tenía catorce años, venía con mucha hambre, tenía una mentalidad un poco particular, me gustaba el fútbol, me gustaba la movida un poco a la manera española, algo rebelde y, claro, al primer encuentro ya hay algunas dificultades de expresión y, luego, el acostumbrarme a llevar mi nombre. Mi padre me llama Floreal siempre, mi madre también y, claro, Floreal para mi no suena más que a una cosa rara, desconocida (...).

Entonces, pues, entre el nombre y la situación, mis primeros arranques de reproche hacia ellos, puesto que me habían dejado, era lo que se nos decía a los hijos de rojos que nos quedamos en España, lleva a veces (...) a algunos roces, pero esos roces se van venciendo sobre la marcha porque, bueno, a mí finalmente el nombre de Floreal no me disgusta, el hecho de ver que los rojos son personas como los demás, pues también me va bien y a medida que va pasando el tiempo, pues hay la ayuda de mis padres, la compresión mejor dicho de mi situación más que la mía acerca de ellos, puesto que yo en cierto modo en un primer arranque hago reproches, ellos comprenden, si les molesto, aceptan esta clase de molestias, puesto que en cierto modo también de alguna manera les pesa el tiempo de separación, luego hay otros problemas que ya son diferentes y el que, bueno, cuando ellos me encuentran tengo ya catorce años y me han dejado de dos (...). Esto es sobre la marcha que finalmente todo se explica, todo se comprende y todo se acepta. 